\title{
Enantioselective PCCP Brønsted acid-catalyzed aminalization of aldehydes
}

\author{
Martin Kamlar ${ }^{1}$, Robert Reiberger ${ }^{1}$, Martin Nigríni ${ }^{1}$, Ivana Císařová ${ }^{2}$ and Jan Veselý ${ }^{* 1}$
}

\author{
Full Research Paper \\ Address: \\ ${ }^{1}$ Department of Organic Chemistry Charles Univerzity, Hlavova \\ 2030/8, Prague 2, 12800, Czech Republic and ${ }^{2}$ Department of \\ Inorganic Chemistry, Charles Univerzity, Hlavova 2030/8, Prague 2, \\ 12800, Czech Republic \\ Email: \\ Jan Veselý* - jxvesely@natur.cuni.cz \\ * Corresponding author \\ Keywords: \\ aminalization; Brønsted acid; organocatalysis; PCCP; \\ pentacarboxycyclopentadiene
}

Beilstein J. Org. Chem. 2021, 17, 2433-2440.

https://doi.org/10.3762/bjoc. 17.160

Received: 27 June 2021

Accepted: 02 September 2021

Published: 16 September 2021

This article is part of the thematic issue "New advances in asymmetric organocatalysis".

Guest Editor: R. Šebesta

(C) 2021 Kamlar et al.; licensee Beilstein-Institut.

License and terms: see end of document.

\begin{abstract}
Here we present an enantioselective aminalization of aldehydes catalyzed by Brønsted acids based on pentacarboxycyclopentadienes (PCCPs). The cyclization reaction using readily available anthranilamides as building blocks provides access to valuable $2,3-$ dihydroquinazolinones containing one stereogenic carbon center with good enantioselectivity (ee up to $80 \%$ ) and excellent yields (up to $97 \%$ ).
\end{abstract}

\section{Introduction}

Nitrogen-containing heterocyclic compounds are commonly occurring in nature and constitute the core structures of many biologically important compounds. An important example of such heterocycles are 2,3-dihydroquinazolinones which scaffold can be found in various compounds exhibiting pharmacological properties [1-6]. Some of them are currently used to treat numerous diseases, such as the diuretic drug fenquizone used for the treatment of hypertension [7,8], or evodiamine, a stimulant used in fat reduction or inflammation [9-11]. Moreover, it was reported that both enantiomers of 2,3-dihydroquinazolinones exhibit different bioactivities $[12,13]$. Thus, the development of enantioselective synthetic strategies towards 2,3- dihydroquinazolinone derivatives has drawn the attention of organic chemists for a long time [14-18], even though the aminal stereocenter is sensitive to racemization [12].

The well-established and straightforward approach in the asymmetric organocatalytic synthesis of molecules with this moiety uses the reaction between aldehydes and anthranilamide building blocks. The advantage of this methodology lies in the fact that both starting materials are readily available, and the enantioselectivity of such cyclization reactions can be controlled by chiral Brønsted acids. In the scope of Brønsted acid catalysis, chiral phosphoric acids (CPA) are dominating as potent cata- 
lysts in various asymmetric transformations [19-23], although the synthesis of these catalysts is expensive and laborious [24]. One of the most frequent examples of CPAs is the binaphthol (BINOL)-derived phosphoric acid class of catalysts, firstly reported by Akiyama [25] and Terada [26]. Soon after, BINOLderived phosphoric acids were employed in the enantioselective synthesis of 2,3-dihydroquinazolinones. The initial report in this area was made by List and co-workers, using an $(S)$-TRIP derivative as the chiral catalyst (Figure 1) [14]. Soon after, Rueping et al. developed a similar methodology catalyzed by other chiral BINOL-phosphoric acids [15]. However, the reaction suffered from limited scope to aromatic aldehydes without an ortho-substitution; the corresponding dihydroquinazolinones were obtained in high yields and with good enantiomeric purities. In 2013, Lin and co-workers published the application of a chiral SPINOL-phosphoric acid in the asymmetric aminalization reaction [27]. Tian's research group de- veloped the synthesis of dihydroquinazolinones from preformed imines instead of aldehydes catalyzed by BINOL-phosphoric acid [17]. The corresponding aminals were prepared with a wide range of substitutions using aromatic, $\alpha, \beta$-unsaturated, or aliphatic imines. Apart from chiral phosphoric acids, chiral quaternary ammonium salts were successfully employed as catalysts in asymmetric dihydroquinazolinone synthesis [18]. Regarding the above-mentioned strategies involving chiral Brønsted acids, we envisioned that chiral pentacarboxycyclopentadiene (PCCP) derivatives could be used in the enantioselective aminalization of aldehydes with anthranilamide derivatives. PCCPs were firstly reported by Otto Diels [28,29], but recently, Lambert and co-workers introduced a new generation, chiral PCCPs (Figure 1) [30]. Due to the high stability of the aromatic cyclopentadienyl anion, PCCPs exhibit a low $\mathrm{p} K_{\mathrm{a}}$ value comparable to that of phosphoric acids. Contrary to chiral phosphoric acids, PCCPs offer less laborious and inexpensive prepa-

first chiral phosporic acid-catalyzed asymmetric aminalization

List (2008) [14]<smiles>CC(C)CC=O</smiles>

(S)-TRIP (10 mol \%)

toluene

$5 \AA \mathrm{MS},-45^{\circ} \mathrm{C}$

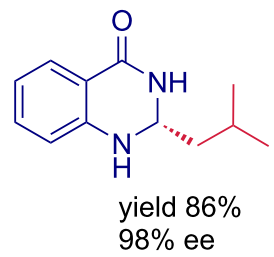

first chiral pentacarboxycyclopentadiene (PCCP)-catalyzed asymmetric transformation

Lambert (2016) [30]<smiles>Oc1ccccc1/N=C/c1ccccc1</smiles><smiles>COC(OC)=C(C)C</smiles>
$\mathrm{R}=(-)$-menthyl $(1 \mathrm{~mol} \%)$
EtOAc, $-78^{\circ} \mathrm{C}$<smiles>[R]C(=O)C1=C(C([R])=O)C(C([R])=O)=C(C([R])=O)C1=C([R])O</smiles><smiles>CC(=O)C(C)(C)[C@H](Nc1ccccc1O)c1ccccc1</smiles>

yield $97 \%$

$97 \%$ ee

this work<smiles>CC(C)CC=O</smiles><smiles>[R]C(=O)C1=C(C([R])=O)C(C([R])=O)=C(C([R])=O)C1=C([R])O</smiles><smiles>CC(C)C[C@@H]1NC(=O)c2ccccc2N1</smiles>

Figure 1: Synthetic strategies employing chiral Brønsted acid catalysis. 
ration protocols $[31,32]$, which makes them an interesting alternative for chiral Brønsted acid-catalyzed transformations [3035].

\section{Results and Discussion}

Herein, we describe our findings regarding the aminalization of aldehydes using PCCP catalysis. Our investigation commenced with the screening of the reaction between anthranilamide (1a) and isovaleraldehyde (2a) in the presence of $10 \mathrm{~mol} \%$ of catalyst II (Table 1). First, we turned our attention to the solvent and temperature effect concerning the yield and the enantioselectivity of the aminalization reaction. While most solvents tested showed to be effective at room temperature, the enantiomeric purity of the corresponding aminal 3a was low in all cases (Table 1, entries 1-5). On the other hand, the yield of 3a was satisfactory in all reactions. In particular, when the reaction between 1a and 2a was performed in toluene, the isolated yield of 3a was almost quantitative (97\%, entry 1 in Table 1). In our pursuit of better enantioselectivity, we continued with the reaction proceeded in toluene at lower temperatures. We found a temperature of $-45{ }^{\circ} \mathrm{C}$ as optimal for the enantiocontrol of the model reaction, affording the product 3a in $90 \%$ yield with an enantiomeric purity of $66 \%$ ee (Table 1 , entry 7). Additionally, the effect of molecular sieves on the course of the reaction was investigated and the obtained results demonstrated that molecular sieves dramatically improved the enantioselectivity (Table 1, entries 9-11). In particular, when the aminalization reaction between 1a and 2a was carried out in the presence of $5 \AA$ molecular sieves, the corresponding product 3a was delivered in high yield $(96 \%)$ and with enantiomeric purity $80 \%$ ee (Table 1 , entry 11). In addition, the effect of the catalyst loading on the course of the reaction was examined. Our data clearly show that reducing the catalyst loading of II caused a significant decrease in the enantioselectivity (Table 1, entries 12 and 13). It is worth mentioning that no differences in the enantioselectivity were observed after a prolonged exposure of compound 3a to the chiral PCCP catalyst II indicating a relatively high stability of the new chiral carbon center in product $\mathbf{3 a}$.

Table 1: Optimization of reaction conditions for the aminalization reaction between $\mathbf{1 a}$ and $\mathbf{2 a}$<smiles>NC(=O)c1ccccc1N</smiles>

$1 a$
$2 a$<smiles>CC(C)CC=O</smiles>

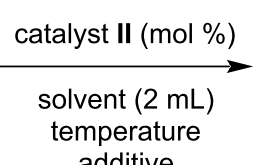
additive
$3 a$<smiles>CC(C)C[C@@H]1NC(=O)c2ccccc2N1</smiles>

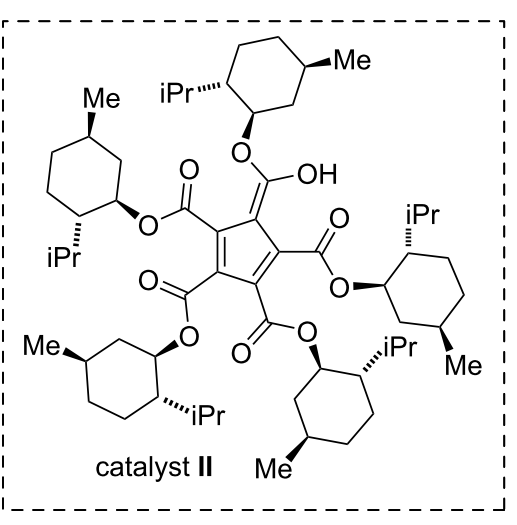

\begin{tabular}{|c|c|c|c|c|c|c|c|}
\hline entry & solvent & $\begin{array}{c}\text { temperature } \\
{\left[{ }^{\circ} \mathrm{C}\right]}\end{array}$ & $\begin{array}{l}\text { cat. loading } \\
{[\mathrm{mol} \%]}\end{array}$ & additive & time $[\mathrm{h}]$ & yield [\%] ${ }^{a}$ & ee $[\%]^{b}$ \\
\hline 1 & toluene & 25 & 10 & - & 0.5 & 97 & 50 \\
\hline 2 & THF & 25 & 10 & - & 1 & 72 & 50 \\
\hline 3 & MTBE & 25 & 10 & - & 1 & 50 & 40 \\
\hline 4 & DCM & 25 & 10 & - & 1 & 93 & 45 \\
\hline 5 & EtOAc & 25 & 10 & - & 1 & 86 & 44 \\
\hline 6 & toluene & 0 & 10 & - & 12 & 96 & 58 \\
\hline 7 & toluene & -45 & 10 & - & 20 & 90 & 66 \\
\hline 8 & toluene & -65 & 10 & - & 48 & 65 & 60 \\
\hline 9 & toluene & -45 & 10 & $3 \AA \mathrm{MS}$ & 20 & 81 & 71 \\
\hline 10 & toluene & -45 & 10 & $4 \AA$ MS & 21 & 73 & 73 \\
\hline 11 & toluene & -45 & 10 & $5 \AA \mathrm{MS}$ & 21 & 96 & 80 \\
\hline 12 & toluene & -45 & 5 & $5 \AA \mathrm{MS}$ & 18 & 91 & 74 \\
\hline 13 & toluene & -45 & 2 & $5 \AA \mathrm{MS}$ & 16 & 86 & 74 \\
\hline
\end{tabular}

alsolated yield; ${ }^{b}$ determined by chiral HPLC. 
Next, a small set of functionalized derivatives of cyclopentadienes as organocatalysts was surveyed in the model reaction (Table 2). Apart from model catalyst II, equipped with five (-)-menthol units, also the sterically less demanding amide-type catalyst III and the thiourea derivative IV were tested (Table 2). First, the diamide-type catalyst III was examined (Table 2, entry 4). Although complete conversion of $\mathbf{1 a}$ and $\mathbf{2 a}$ was achieved after a significantly prolonged time ( 7 days), the aminal 3a was isolated in a good yield of $60 \%$. Unfortunately, the reaction proceeded nearly in a racemic fashion. An inefficient catalyst showed up to be the PCCP catalyst derivatized with thiourea functional units (IV); a formation of 3a was not observed even after prolonged reaction time (Table 2, entry 5). It is also worth mentioning that the non-catalyzed reaction did not deliver the corresponding product 3a even after 40 hours (Table 2, entry 1). Based on the results summarized in Table 2, the chiral PCCP catalyst II was selected as the optimal catalyst.

With the optimized reaction conditions in our hands, we continued investigating the scope of the reaction. First, we focused on the reactivity of anthranilamide (1a) with various aldehydes 2a-j (Scheme 1). Generally, aliphatic aldehydes delivered the cyclic aminals 3a-d in excellent yields between 95-97\% and enantiomeric purities between $74-80 \%$ ee. However, the sterically demanding pivalaldehyde (2c) needed a prolonged reaction time to reach the complete conversion. In addition, a significant drop in the enantioselectivity (10\% ee) of 3c was observed. Also, benzaldehyde derivatives were successfully tested in the aminalization reaction. However, a decrease in reactivity and enantioselectivity was observed when compared to aliphatic aldehydes. The corresponding products $\mathbf{3 e - j}$ were isolated in lower yields (58-83\%) with enantiomeric purities ranging from 20 to $70 \%$ ee. For example, when benzaldehydes substituted with fluorine or chlorine in the para-position were employed in catalytic reaction with anthranilamide (1a), the corresponding derivatives $\mathbf{3 i} \mathbf{i} \mathbf{j}$ were isolated in 58 and $69 \%$ yield, respectively. The rates of enantioselectivity for both reactions were lower and averaged only around $50 \%$. In addition, the role of an electron-donating methyl group on the aromatic ring was investigated. When $p$-tolualdehyde (1f) was used in the cyclization reaction with anthranilamide (1a), the corresponding aminal 3f was obtained in high yield (83\%) and with good enantiomeric excess of $70 \%$ ee. On the other hand, when $m$ - or $o$-tolualdehyde were employed in aminalization reaction, a sig-

Table 2: Catalyst screening of the aminalization reaction between $\mathbf{1 a}$ and $\mathbf{2 a}$<smiles>CC(C)CC(=O)N[C@H]1NC(=O)c2ccccc2N[C@@H]1CC(C)C</smiles><smiles></smiles>

I

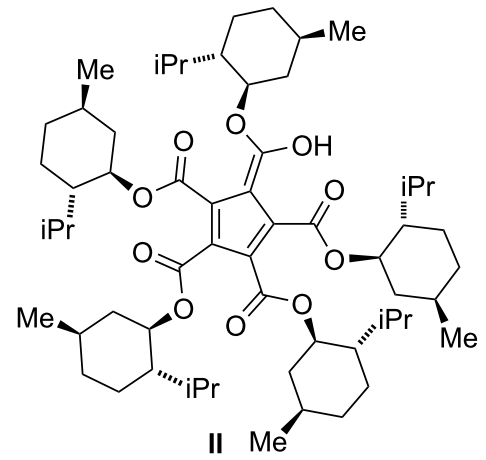<smiles>COC(=O)C1=C(C(=O)NC2CCCc3ccccc32)C(C(=O)OC)=C(C(=O)OC)C1=C(O)NC1CCCc2ccccc21</smiles>

III<smiles>COC(=O)C1=C(C(=O)OC)C(C(=O)OC)=C(C(=O)OC)C1=C(O)N[C@@H]1CCCC[C@@H]1NC(=S)Nc1cc(C(F)(F)F)cc(C(F)(F)F)c1</smiles>

IV

\begin{tabular}{ccccc}
\hline entry & catalyst & time [h] & yield [\%] \\
\hline 1 & - & 40 & n.d. & n.d. \\
2 & I & 16 & 95 & 0 \\
3 & II & 21 & 96 & 80 \\
4 & III & 168 & 60 & 2 \\
5 & IV & 168 & n.d. & n.d. \\
\hline
\end{tabular}

assolated yield; ${ }^{b}$ determined by chiral HPLC. 


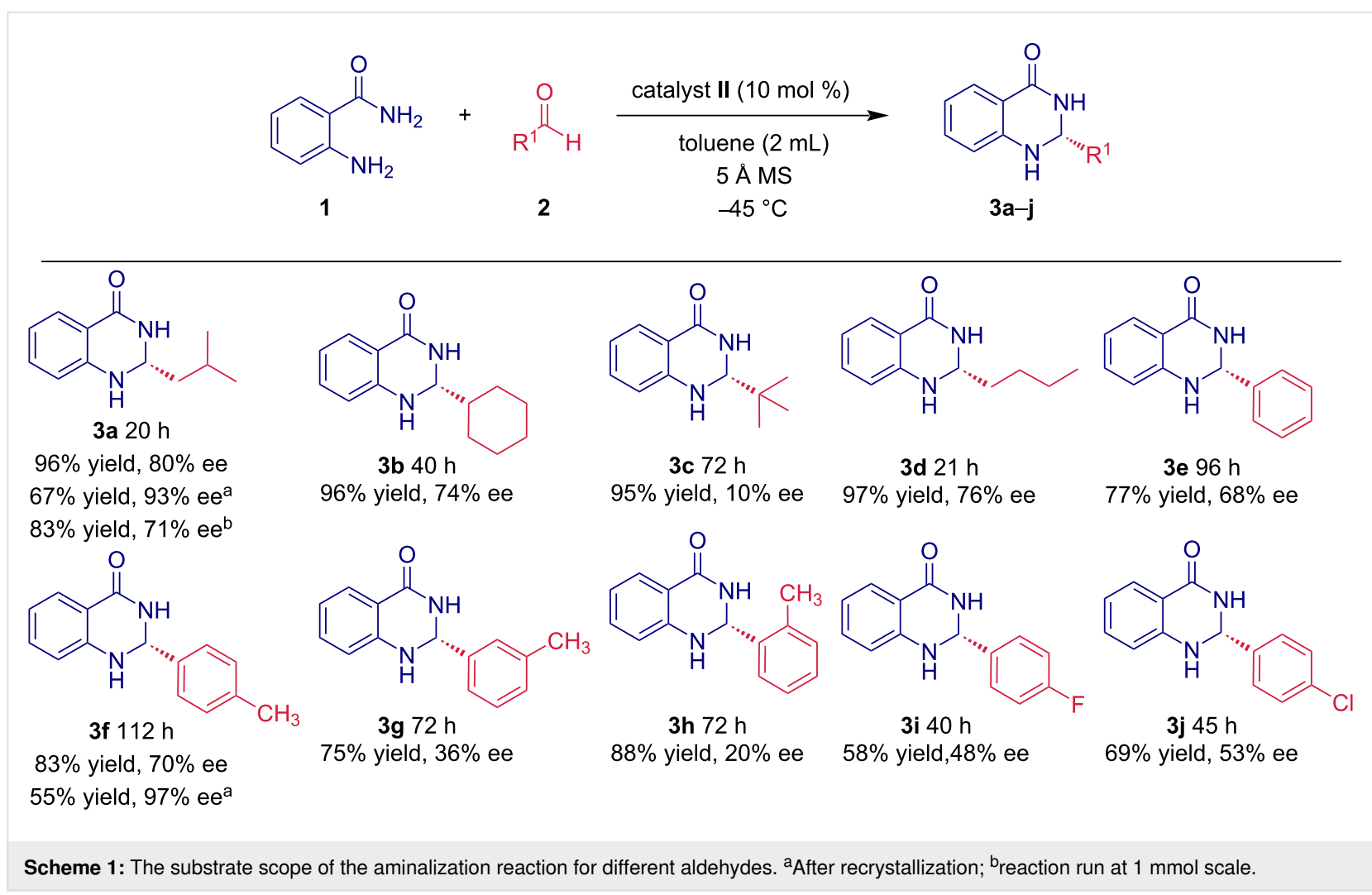

nificant drop in the enantioselectivity was observed. Aminals $\mathbf{3 g}$ and $\mathbf{3 h}$ were obtained with 36 and $20 \%$ ee, respectively. We have also tested the reaction between anthranilamide (1a) and isovaleraldehyde (2a) in $1 \mathrm{mmol}$ scale. The obtained results suggested that the reaction proceeded with slightly lower efficiency giving product 3a in $83 \%$ yield and $71 \%$ ee. On the other hand, we found that the desired product of aminalization reaction could be readily obtained in higher enantiomeric purity after crystallization from ethyl acetate. This was demonstrated for products $3 \mathbf{a}$ and $\mathbf{3 f}$, that were obtained in enantiomeric purities of $93 \%$ and $97 \%$ ee, respectively (Scheme 1).

Next, we turned our attention to the substitution of anthranilamide (Scheme 2). First, the effect of bromine as a slightly electron-withdrawing substituent on the aromatic ring was investigated. The position of bromine on the aromatic ring had a dramatic effect on the enantiomeric purity of the formed products $3 \mathbf{k}-\mathbf{n}$. When a bromine substituent is introduced in the " 3 " position of anthranilamide, the enantiomeric enrichment of aminal 3k reached only $30 \%$ ee. In contrast, substitution with bromine either in position " 4 " and " 5 " led to a formation of products $\mathbf{3} \mathbf{I}$ and $\mathbf{3 m}$ with enantiomeric purities of $70 \%$ ee and $80 \%$ ee, respectively. Finally, reaction with anthranilamide substituted with bromine in position " 6 " led to corresponding aminal 3n with an enantiomeric excess of $66 \%$ ee. We also increased the enantiomeric purity of $\mathbf{3 1}$ from $70 \%$ to $80 \%$ ee after crystallization from ethyl acetate. When anthranilamide substituted with a chlorine in the " 5 " position was used, the enantioselectivity of the reaction reached a value of $76 \%$ ee, and the yield of the corresponding aminal 30 exceeded $80 \%$. Next, the effect of a strongly electron-withdrawing nitro group present on anthranilamide moiety was investigated. The reaction carried out in toluene did not reach a complete conversion even after a prolonged reaction time. When more polar THF was used as the solvent, the corresponding product $\mathbf{3 p}$ was obtained after 40 hours in an excellent yield of $96 \%$; however, the enantiomeric purity of $\mathbf{3 p}$ was only $42 \%$ ee. Anthranilamides containing electron-donating methyl and methoxy groups were also well-tolerated in the aminalization reaction. For example, reaction with anthranilamide bearing a methyl group in the " 4 " position delivered product $\mathbf{3 q}$ in good yield (80\%) and enantiopurity (69\% ee). A higher yield (96\%) and enantiopurity ( $72 \%$ ee) was reached with anthranilamide 1r, having a methyl group in the position " 5 ". To further broaden the scope of the aminalization reaction, we prepared 2-(2-aminophenyl)acetamide (1t) and tested it in the reaction with isovaleraldehyde (2a) to access benzodiazepinone derivatives. The reaction proceeded smoothly with complete conversion within 24 hours, yielding the desired benzodiazepinone derivative $\mathbf{3 t}$ in $55 \%$. However, the enantiomeric purity dropped significantly to $35 \%$ ee. Additionally, we tested the influence of substitution of the aromatic amine and prepared the benzyl-protected anthranilamide 1u. Unfortu- 
<smiles>[R]Nc1cc[R1]cc1C(N)=O</smiles><smiles>CC(C)C[C@@H]1NC(=O)c2cccc(Br)c2N1</smiles>
$71 \%$ yield, $30 \%$ ee<smiles>CC(C)C[C@@H]1NC(=O)c2ccc(Br)cc2N1</smiles>

$89 \%$ yield, $70 \%$ ee $62 \%$ yield, $80 \%$ ee ${ }^{a}$<smiles>CC(C)C[C@@H]1NC(=O)c2cc(Br)ccc2N1</smiles>

$78 \%$ yield, $80 \%$ ee<smiles>CC(C)C[C@@H]1NC(=O)c2c(Br)cccc2N1</smiles><smiles>CC(C)C[C@@H]1NC(=O)c2cc(Cl)ccc2N1</smiles>

$3072 \mathrm{~h}$<smiles>CC(C)C[C@@H]1NC(=O)c2ccc([N+](=O)[O-])cc2N1</smiles>

$3 p 40 h^{b}$

$96 \%$ yield, $42 \%$ ee<smiles>Cc1ccc2c(c1)N[C@H](CC(C)C)NC2=O</smiles>

$3 q 84 \mathrm{~h}$

$80 \%$ yield, $69 \%$ ee<smiles>Cc1ccc2c(c1)C(=O)N[C@@H](CC(C)C)N2</smiles>

$96 \%$ yield, $72 \%$ ee<smiles>COc1ccc2c(c1)C(=O)N[C@@H](CC(C)C)N2</smiles>

3s $24 \mathrm{~h}$

$74 \%$ yield, $64 \%$ ee<smiles>CC(C)C[C@@H]1NC(=O)Cc2ccccc2N1</smiles>

3t $24 \mathrm{~h}$ $55 \%$ yield, $35 \%$ ee<smiles>CC(C)C[C@@H]1NC(=O)c2ccccc2N1</smiles>

$3 \mathrm{u} 120 \mathrm{~h}$ no conversion

Scheme 2: The substrate scope of the intermolecular aminalization reaction for anthranilamide derivatives. ${ }^{\text {aAfter }}$ recrystallization; ${ }^{\mathrm{b}}$ THF used as a reaction solvent.

nately, the reaction between $\mathbf{1} \mathbf{u}$ and isovaleraldehyde (2a) did not deliver the corresponding product $3 \mathbf{u}$ even after a prolonged reaction time.

To determine the absolute configuration of aminals 3a-t, derivative $\mathbf{3 I}$ was subjected to $\mathrm{X}$-ray crystallographic analysis. The absolute configuration of the stereogenic center (C1) was assigned as $R$ (Figure 2, for details see Supporting Information File 1) [36], which is in agreement with the configuration of aminals obtained by List and co-workers [14].

\section{Conclusion}

In summary, we have reported an organocatalytic asymmetric aminalization reaction between aldehydes and anthranilamides catalyzed by a PCCP catalyst as a cheap and readily available option to conventional chiral BINOL phosphoric acids. The reaction tolerates a wide range of substitutions of anthranilamides and aromatic and aliphatic aldehydes, yielding the corresponding dihydroquinazolinones in excellent yields (up to $97 \%$ ) and enantiopurities up to $80 \%$ ee. We demonstrated that bulkiness of aldehydes negatively affected the enantiocontrol of

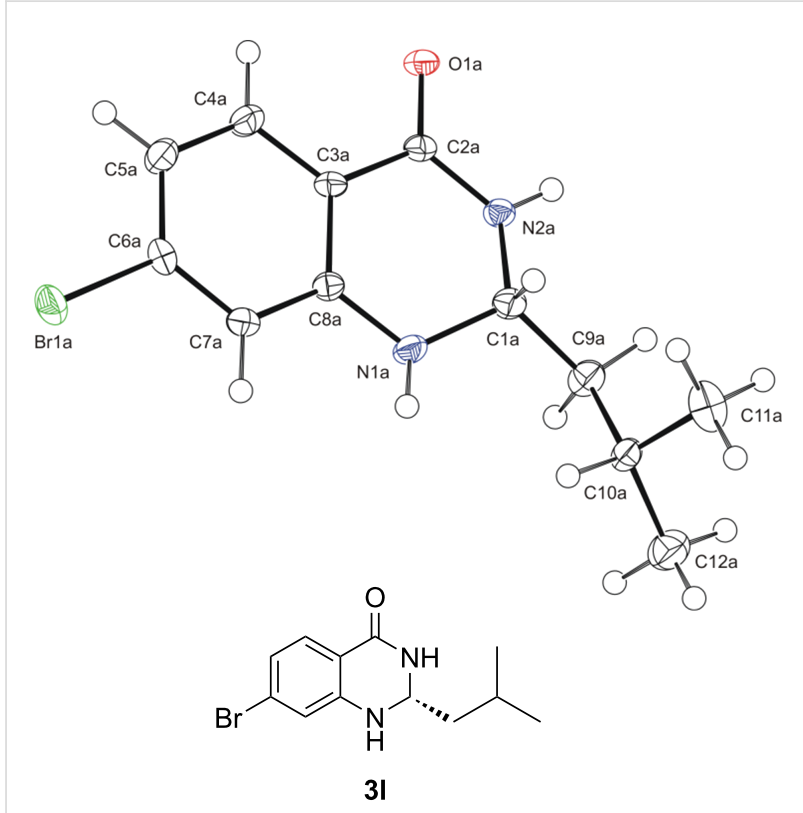

Figure 2: X-ray single-crystal structure of aminal 3I with the displacement ellipsoids drawn at the $30 \%$ probability level. 
the process, and highly enantiomerically enriched dihydroquinazolinones can be achieved by crystallization (up to $97 \%$ ee). The developed methodology can also be used to form tetrahydrobenzodiazepinones; however, a significant drop in the yield and enantioselectivity was observed.

\section{Supporting Information}

\section{Supporting Information File 1}

General synthetic procedures, characterization of compounds, X-ray experimental data, and copies of ${ }^{1} \mathrm{H}$ and ${ }^{13} \mathrm{C}$ NMR spectra.

[https://www.beilstein-journals.org/bjoc/content/ supplementary/1860-5397-17-160-S1.pdf]

\section{Funding}

The work was supported by the Czech Science Foundation (2029336S). This work has been supported by Charles University Research Centre program No. UNCE/SCI/014. The authors acknowledge the support of the Charles University program START No. CZ.02.2.69/0.0/0.0/19_073/0016935 (START/SCI/ 084).

\section{ORCID ${ }^{\circledR}$ iDs}

Martin Kamlar - https://orcid.org/0000-0001-9115-9858 Robert Reiberger - https://orcid.org/0000-0001-7878-9310 Ivana Císařová - https://orcid.org/0000-0002-9612-9831 Jan Veselý - https://orcid.org/0000-0001-5198-8950

\section{Preprint}

A non-peer-reviewed version of this article has been previously published as a preprint: https://doi.org/10.3762/bxiv.2021.48.v1

\section{References}

1. Auti, P. S.; George, G.; Paul, A. T. RSC Adv. 2020, 10, 41353-41392. doi:10.1039/d0ra06642g

2. Xu, Z.; Zhang, Y.; Fu, H.; Zhong, H.; Hong, K.; Zhu, W. Bioorg. Med. Chem. Lett. 2011, 21, 4005-4007. doi:10.1016/j.bmcl.2011.05.002

3. Levin, J. I.; Chan, P. S.; Bailey, T.; Katocs, A. S., Jr.; Venkatesan, A. M. Bioorg. Med. Chem. Lett. 1994, 4, 1141-1146. doi:10.1016/s0960-894x(01)80244-4

4. Horton, D. A.; Bourne, G. T.; Smythe, M. L. Chem. Rev. 2003, 103, 893-930. doi:10.1021/cr020033s

5. Badolato, M.; Aiello, F.; Neamati, N. RSC Adv. 2018, 8, 20894-20921. doi:10.1039/c8ra02827c

6. Bonola, G.; Da Re, P.; Magistretti, M. J.; Massarani, E.; Setnikar, I. J. Med. Chem. 1968, 11, 1136-1139. doi:10.1021/jm00312a007

7. Selvam, T. P.; Kumar, P. V. Res. Pharm. 2011, 1 (1), 1-21.

8. Angelino, P. F.; Alvino-Demartino, A.; Mappa, R.; Donati, C. Int. J. Clin. Pharmacol., Ther. Toxicol. 1985, 23, 501-505.
9. Yu, H.; Jin, H.; Gong, W.; Wang, Z.; Liang, H. Molecules 2013, 18, 1826-1843. doi:10.3390/molecules18021826

10. Sun, Q.; Xie, L.; Song, J.; Li, X. J. Ethnopharmacol. 2020, 262, 113164 doi:10.1016/j.jep.2020.113164

11. Rebhun, J. F.; Roloff, S. J.; Velliquette, R. A.; Missler, S. R. Fitoterapia 2015, 101, 57-63. doi:10.1016/j.fitote.2014.12.009

12. Chinigo, G. M.; Paige, M.; Grindrod, S.; Hamel, E.; Dakshanamurthy, S.; Chruszcz, M.; Minor, W.; Brown, M. L. J. Med. Chem. 2008, 51, 4620-4631. doi:10.1021/jm800271c

13. Uzunov, D. P.; Zivkovich, I.; Costa, E.; Guidotti, A.; Pirkle, W. H. J. Pharm. Sci. 1995, 84, 937-942. doi:10.1002/jps.2600840807

14. Cheng, X.; Vellalath, S.; Goddard, R.; List, B. J. Am. Chem. Soc. 2008, 130, 15786-15787. doi:10.1021/ja8071034

15. Rueping, M.; Antonchick, A. P.; Sugiono, E.; Grenader, K. Angew. Chem., Int. Ed. 2009, 48, 908-910. doi:10.1002/anie.200804770

16. Honjo, T.; Phipps, R. J.; Rauniyar, V.; Toste, F. D. Angew. Chem., Int. Ed. 2012, 51, 9684-9688. doi:10.1002/anie.201205383

17. Cheng, D.-J.; Tian, Y.; Tian, S.-K. Adv. Synth. Catal. 2012, 354, 995-999. doi:10.1002/adsc.201100849

18. Ayyanar, S.; Vijaya, P. K.; Mariyappan, M.; Ashokkumar, V.; Sadhasivam, V.; Balakrishnan, S.; Chinnadurai, C.; Murugesan, S. New J. Chem. 2017, 41, 7980-7986. doi:10.1039/c7nj00538e

19. Li, X.; Song, Q. Chin. Chem. Lett. 2018, 29, 1181-1192. doi:10.1016/j.cclet.2018.01.045

20. Terada, M. Curr. Org. Chem. 2011, 15, 2227-2256. doi:10.2174/138527211796150732

21. Maji, R.; Mallojjala, S. C.; Wheeler, S. E. Chem. Soc. Rev. 2018, 47, 1142-1158. doi:10.1039/c6cs00475j

22. Terada, M. Bull. Chem. Soc. Jpn. 2010, 83, 101-119. doi:10.1246/bcsj.20090268

23. Wu, H.; He, Y.-P.; Shi, F. Synthesis 2015, 47, 1990-2016. doi:10.1055/s-0034-1378837

24. Ahmed, I.; Clark, D. A. Org. Lett. 2014, 16, 4332-4335. doi:10.1021/ol502126r

25. Akiyama, T.; Itoh, J.; Yokota, K.; Fuchibe, K. Angew. Chem., Int. Ed. 2004, 43, 1566-1568. doi:10.1002/anie.200353240

26. Uraguchi, D.; Terada, M. J. Am. Chem. Soc. 2004, 126, 5356-5357. doi:10.1021/ja0491533

27. Huang, D.; Li, X.; Xu, F.; Li, L.; Lin, X. ACS Catal. 2013, 3, 2244-2247. doi:10.1021/cs400591u

28. Diels, O. Ber. Dtsch. Chem. Ges. A 1942, 75, 1452-1467. doi:10.1002/cber.19420751206

29. Diels, O.; Kock, U. Justus Liebigs Ann. Chem. 1944, 556, 38-50. doi:10.1002/jlac.19445560105

30. Gheewala, C. D.; Collins, B. E.; Lambert, T. H. Science 2016, 351, 961-965. doi:10.1126/science.aad0591

31. Radtke, M. A.; Dudley, C. C.; O'Leary, J. M.; Lambert, T. H. Synthesis 2019, 51, 1135-1138. doi:10.1055/s-0037-1611650

32. Gheewala, C. D.; Radtke, M. A.; Hui, J.; Hon, A. B.; Lambert, T. H. Org. Lett. 2017, 19, 4227-4230. doi:10.1021/acs.orglett.7b01867

33. Hammersley, G. R.; Nichol, M. F.; Steffens, H. C.; Delgado, J. M.; Veits, G. K.; Read de Alaniz, J. Beilstein J. Org. Chem. 2019, 15, 1569-1574. doi:10.3762/bjoc.15.160

34. Gheewala, C. D.; Hirschi, J. S.; Lee, W.-H.; Paley, D. W.; Vetticatt, M. J.; Lambert, T. H. J. Am. Chem. Soc. 2018, 140, 3523-3527. doi:10.1021/jacs.8b00260

35. Sui, Y.; Cui, P.; Liu, S.; Zhou, Y.; Du, P.; Zhou, H. Eur. J. Org. Chem 2018, 215-218. doi:10.1002/ejoc.201701561 
36. CCDC 2081064 for $\mathbf{3}$ contains the supplementary crystallographic data for this paper. These data can be obtained free of charge from The Cambridge Crystallographic Data Centre via http://www.ccdc.cam.ac.uk/data_request/cif

\section{License and Terms}

This is an Open Access article under the terms of the Creative Commons Attribution License

(https://creativecommons.org/licenses/by/4.0). Please note that the reuse, redistribution and reproduction in particular requires that the author(s) and source are credited and that individual graphics may be subject to special legal provisions.

The license is subject to the Beilstein Journal of Organic Chemistry terms and conditions:

(https://www.beilstein-journals.org/bjoc/terms)

The definitive version of this article is the electronic one which can be found at:

https://doi.org/10.3762/bjoc. 17.160 